\title{
Tabellenliste
}

Original Übersetzung

Tabelle 1

Tabelle 2

Tabelle 3

Tabelle 4

Tabelle 5

Tabelle 6

Tabelle 7

Tabelle 8

Tabelle 9

Tabelle 10

Tabelle 11

Tabelle 12

Tabelle 13

Tabelle 14

Tabelle 15

Tabelle 16

Tabelle 17

Tabelle 18

Tabelle 19

Tabelle 20

Tabelle 21

Tabelle 22

Tabelle 23

Tabelle 24

Tabelle 25

Tabelle 26

Tabelle 27

Tabelle 28

Tabelle 29

Tabelle 30

Tabelle 31
Gesamter Ausfuhr- und Einfuhrhandel Irans .........7

Ein- und Ausfuhr-Verhältnisse

7.

Handel Irans mit verschiedenen Ländern...............

Wichtige Einfuhrwaren Irans

Betreffs eingeführter Stoffe 1328-1329 ...................

Wichtige Einfuhrgüter

13

Wachstum und Rückgang der Einfuhr

14

15

16

Wichtige Ausfuhrwaren Irans

17

18

19

20

22

Reisexport..

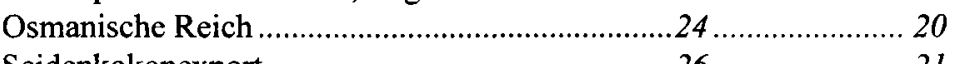

Seidenkokonexport .........................................26................. 21

Seidenexport..................................................26................. 21

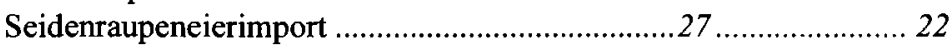

Gesamter Lederexport, Anteil Russlands

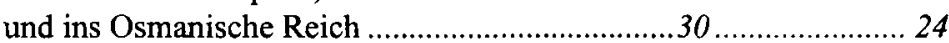

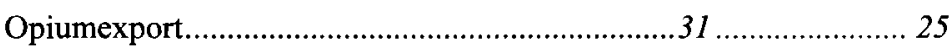

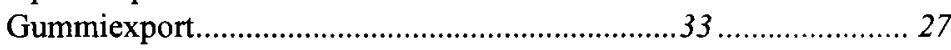

Export von Wolle (unbearbeitet)...........................33 …............... 27

Wasserpfeifen- und Pfeifentabakexport.................34 f.................. 28

Export von lebenden Tieren ..................................................... 30

Ein- und Ausfuhr der wichtigen Häfen im Jahr

des Hundes 1328-1329 ........................................................... 32

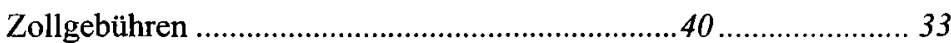

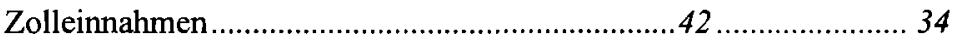

Einnahmen jedes einzelnen Zollhafens und

seine administrativen Kosten im Jahr des

Hundes 1328-1329

43

35

Einnahmen jedes einzelnen Zollhafens und

seine administrativen Kosten im Jahr des

Büffels 1331-1332.

.43

Versandkosten über Russland und die Häfen

Anzali, Astara, Maschhadsar, Bandardjez

62

Versandkosten aus dem Ausland nach Iran

(über den Südweg)

.63

53

Schifffahrt im Persischen Golf im Jahr

des Hundes 1328-1329.

.64

54 
Tabelle 32 Verkehr der russischen Schiffe in den Häfen des Kaspischen Meeres im Jahr des Hundes

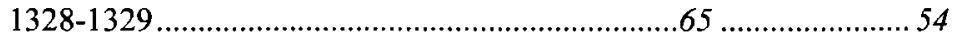

Tabelle 33 Darstellung der gesamten Steuern Irans im Jahr des Büffels 1306 $123 \ldots \ldots \ldots \ldots \ldots \ldots . . . . . . . .102$

Tabelle 34 Darstellung der Opiumausfuhr aus Bandar Abbas und Buschir von 1288 bis $1314 \ldots \ldots 127$.................... 106

Tabelle 35 Darstellung der Produktion von Opium (und Seide) der Provinz Gilan von 1047 bis 1307 128 .................... 107

Tabelle 36 Einnahmen aus der Verpachtung der Zollämter innerhalb der 20 Jahre vor der Pachtaufhebung.....131 .................... 109

Tabelle 37 Darstellung der Tätigkeit des Münzhofs in den Jahren des Schweins 1329-1330 und der Ratte 1330-31 140

Tabelle 38 Staatseinnahmen in den Finanzjahren 1329 und 1330 145

Tabelle 39 Staatliche Geldeinnahmen im Finanzjahr 1303

Tabelle 40 Darstellung der Staatsausgaben bezüglich der Zentral- und Provinzverwaltungen im Jahr der Ratte 1330. .147

Tabelle 41 Darstellung der Staatsdarlehen Irans bis 6. Scha'ban 1331 152

Tabelle 42 Der geschätzte Haushalt fürs Finanzjahr des Hundes 1328-1329. $157-164$

Tabelle 43

Tabelle 44 Kurzfassung der Einnahmen und Ausgaben Irans im Jahr der Ratte 1330-1331 165

Darstellung der iranischen Ein- und Ausfuhr von Gold- und Silbermünzen, sowie Silber- und Goldbarren (auch Weißgold) innerhalb von sechs Jahren ab dem Finanzjahr 1325 176 146

Tabelle 45 Umrechnungskurs ausländischer Währungen zum Kran in den Jahren des Weltkrieges ..............177

Tabelle 46 Handel Irans im Jahr des Büffels 1331-1332 .190 158

\section{Liste der im Buch angegebenen Karten}

Original Übersetzung

1. Plan der Provinz Gilan ...............................................................23 _..................... 19

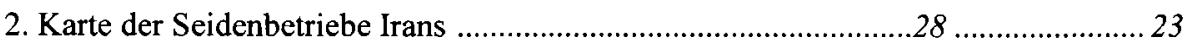

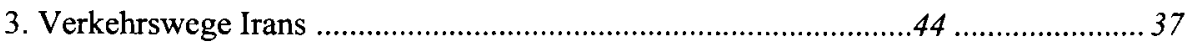

4. Karte der Kupferlager in der Provinz Chorasan ............................73 ......................61 61

5. Konzessionsgebiete der Bergwerke von Qaradje Dagh ..............102 ....................85 85

6. Wichtige Routen Irans mit Streckenlängen und -höhen ................am Ende ............. 165 